\title{
WSPÓLCZESNA REWOLUCJA OBYCZAJOWA, CZYLI AWANTURA O ROCK AND ROLLA I BIKINI
}

\section{Wprowadzenie}

Niniejszy artykuł nawiązuje do publikacji Jędrzeja Stanisławka pt. Współczesna rewolucja obyczajowa ${ }^{1}$, która prezentuje tezy opisujące zmiany obyczajów i kultury, nazwane w artykule „współczesną rewolucją aksjologiczno-obyczajową" (dalej WRO). Kulturze i obyczajom tradycyjnym Autor przeciwstawia kulturę i obyczaje współczesne ${ }^{2}$, następnie przedstawia tezy odnośnie do obiektywnych i subiektywnych źródeł przemian w kulturze w kontekście ekonomicznym ${ }^{3}$, a dokładniej w kontekście dawnych i nowych form poszerzania rynków zbytu ${ }^{4}$. Prezentuje także pogląd na sposoby upowszechniania kultury i obyczajowości współczesnej w aspekcie zmian politycznych a także przyczyny leżące u podstaw likwidacji (zaniku - komentarz R. B.) kultury tradycyjnej5 .

Podjęta przeze mnie polemika ma dwa cele. Pierwszy cel jest konfrontatywno-uzupełniający - wykażę nieadekwatność argumentacji w zakresie: (1) logicznym - nieuzasadniony analitycznie, dychotomiczny podział kultury na tradycyjną i współczesną; oraz (2) historycznym - braki faktograficzne. Drugim celem jest zwrócenie uwagi na to, że poruszana

\footnotetext{
J. Stanisławek, Współczesna rewolucja obyczajowa, „Edukacja Filozoficzna” 2016, nr 62, s. $85-96$.

Tamże, s. 86.

Tamże, s. 86-88.

Tamże, s. 90.

5 Tamże, s. 92-95.
} 
problematyka zalicza się do filozofii polityki i o ten kontekst WRO powinna być uzupełniona.

\section{Zarys teorii współczesnej rewolucji obyczajowej \\ 1.1. Kultura i obyczaje tradycyjne vs. kultura i obyczaje współ- czesne}

Zaproponowany przez Stanisławka podział przeciwstawiający kulturę i obyczajowość tradycyjną kulturze i obyczajowości współczesnej jest problematyczny. Dla uproszczenia posłużmy się odpowiednio sygnaturami TRADYCYJNY i WSPÓŁCZESNY: kultura ${ }_{\text {TRADYCYJNA }}$, dalej $\mathrm{K}_{\mathrm{T}}$, i obyczaje $_{\text {TRA- }}$ DYCYJNE , dalej $\mathrm{O}_{\mathrm{T}}$, oraz kultura ${ }_{\text {WSPÓŁCZESNA }}$, dalej $\mathrm{K}_{\mathrm{W}}$, i obyczaje wSPÓŁCZESNE' dalej $\mathrm{O}_{\mathrm{w}}$.

Autor poddanego dyskusji artykułu stwierdza:

[1] W sferze aksjologii kulturę tradycyjną wypiera kultura współczesna. Elitaryzm, idealizm i ascetyzm (wyznaczniki kultury tradycyjnej) ustępują miejsce egalitaryzmowi, utylitaryzmowi i hedonizmowi ${ }^{6}$.

Zauważmy, że w powyższym kontekście określenie „kultura” jest użyte jako termin, w którego zakresie wyróżnia się $\mathrm{K}_{\mathrm{T}}$ - której wyznacznikami są elitaryzm, idealizm, ascetyzm - oraz $\mathrm{K}_{\mathrm{W}}$ - której wyznacznikami są egalitaryzm, utylitaryzm, hedonizm. Określenie „obyczaje” nie zostało użyte jako termin, można jednak domyślić się, że obyczaje (oraz wartości $\mathrm{i}$ idee) wynikają odpowiednio $\mathrm{z}$ wartości depozytu semantycznego ${ }^{7} \mathrm{~K}_{\mathrm{T}}$ i $\mathrm{K}_{\mathrm{W}}$. Następnie wyjaśniona zostaje funkcja $\mathrm{K}_{\mathrm{T}} \mathrm{i} \mathrm{K}_{\mathrm{W}}$ :

[2] Kultura tradycyjna jako cel życia wskazuje realizację ideałów. Odpowiednio do stopnia realizacji ideałów ludzi uważa się tutaj za lepszych albo gorszych, a pohamowanie naturalnych skłonności stanowi powód do chwały ${ }^{8}$.

\footnotetext{
6 Tamże, s. 85.

7 Depozyt semantyczny - jakakolwiek wartość znacząca. Depozyt semantyczny charakteryzuje się tym, że postrzegający wie, że to, co postrzega ma jakieś znaczenie; $X$ coś znaczy, lecz nie wiem, co znaczy. Pozwala to na uruchomienie procedury „poszukiwania znaczenia”. Więcej na ten temat piszę w artykule R. Boroch, Formalna Analiza Konceptualna - Reprezentacja Wiedzy - Przektad, „Roczniki Humanistyczne. Studia Translatoryczne” 2013, t. 61, nr 6, s. 121-154; URL: <http:// czasopisma.tnkul.pl/index.php/rh/article/view/4898>.
}

8 J. Stanisławek, dz. cyt., s. 85. 
[3] Kultura współczesna jako cel życia wskazuje doznawanie przyjemności. W jej ujęciu, podstawową wartością jest pożytek, a pożytkiem największym przyjemność osobista ${ }^{9}$.

Teza [1] wskazuje na cechy $\mathrm{K}_{\mathrm{T}} \mathrm{i} \mathrm{K}_{\mathrm{w}}$, natomiast tezy [2] i [3] definiują $\mathrm{K}_{\mathrm{T}}$ i $\mathrm{K}_{\mathrm{W}}$ poprzez cele, jakie każda $\mathrm{z}$ nich wyznacza człowiekowi: dla $\mathrm{K}_{\mathrm{T}}$ tym celem będzie realizacja ideałów, a dla $\mathrm{K}_{\mathrm{W}}$ - doznawanie przyjemności (hedonizm).

Rozszerzeniem tezy [3] jest teza [4]:

[4] Utylitaryzm (kult pożytku) oraz hedonizm (kult przyjemności) uzupełnia idea powszechnej równości - co formalnie zdaje się niekonsekwentne, gdyż zgodnie z zasadą użyteczności ludzi powinno się dzielić na bardziej i mniej pożytecznych $^{10}$.

Teza [4] doprecyzowuje jak jest rozumiany utylitaryzm oraz hedonizm; ponadto wprowadza element uzupełniający, jakim jest idea powszechnej równości, co prowadzi do konkluzji, że „pożytek” jest determinantą $\mathrm{K}_{\mathrm{W}}$.

Podsumowując. Stanisławek proponuje analizę zjawisk kultury, opierając się na przeciwstawieniu sobie kultury tradycyjnej $\left(\mathrm{K}_{\mathrm{T}}\right)$ i kultury współczesnej $\left(\mathrm{K}_{\mathrm{W}}\right)$. Każdej $\mathrm{z}$ nich przypisuje też cechy - dla $\mathrm{K}_{\mathrm{T}}$ są to elitaryzm, idealizm, ascetyzm, dla $\mathrm{K}_{\mathrm{W}}$ zaś są to egalitaryzm, utylitaryzm, hedonizm. Słabością tej propozycji jest to, że cechy $\mathrm{K}_{\mathrm{T}}$ i $\mathrm{K}_{\mathrm{W}}$ znajdują się w funkcji indeksowej ${ }^{11}$, co oznacza możliwość poszerzenia o inne cechy, zależne od dynamicznego i nieustannie zmieniającego się kontinuum społeczno-kulturowego.

Problematyczną tezą odnośnie do $\mathrm{O}_{\mathrm{T}} \mathrm{i}_{\mathrm{W}}$ jest to, że odstępstwa od reguł (zasad) $\mathrm{O}_{\mathrm{T}}$ skutkują karą naturalną (kłopoty życiowe) albo społeczną (społeczne potępienie) ${ }^{12}$. Ma to ilustrować przykład szkoły - ta dawna, zdaniem Autora, była surowa, stawiała uczniom wymagania, groziła kon-

\footnotetext{
Tamże, s. 85.

10 Tamże, s. 85-86.

11 Zob. T. L. Short, Peirce's Theory of Signs, Cambridge University Press, New York 2007, https://doi.org/10.1017/CBO9780511498350

12 Tamże, s. 86.
} 
sekwencjami, podczas gdy we współczesnej panuje przyzwolenie, wyrozumiałość i miłosierdzie ${ }^{13}$.

\subsection{Krytyka}

\subsubsection{Metodologia}

Konstruowanie opisu kultury w oparciu o dychotomię, w której jeden $\mathrm{z}$ elementów stanowi przeciwieństwo drugiego - w tym wypadku $\mathrm{K}_{\mathrm{T}}$ jest przeciwieństwem (antytezą) $\mathrm{K}_{\mathrm{w}}$ - jest epistemiczne najgorszym z możliwych rozwiązaniem, ponieważ prowadzi do rozumowania $p \vee \neg p-$ co ma poważne reperkusje analityczne. Wątpliwa jest bowiem moc wyjaśniająca podziału $\mathrm{K}_{\mathrm{T}} \mathrm{i} \mathrm{K}_{\mathrm{w}}$, ponieważ nie znajduje potwierdzenia w możliwych do zaobserwowania faktach. Zjawiska kulturowe mają charakter szczególny. Są one: (1) złożone - odnoszą się do wielu struktur społecznych jednocześnie; (2) dynamiczne - zmiany jakościowe i ilościowe nie są obserwowalne w trakcie ich zachodzenia; (3) wielowymiarowe - kultura wkracza we wszystkie obszary życia ludzkiego, itd. Cechy (1)-(3), które tu przykładowo wymieniam, konstytuują tzw. kontinuum kulturowe czy społeczne. Innymi słowy, nawiązując do terminologii Stanisławka, do proponowanego podziału $\mathrm{K}_{\mathrm{T}}$ i $\mathrm{K}_{\mathrm{W}}$ można wprowadzić inne $\mathrm{K}$, np. hybrydowe $\mathrm{K}_{n}$, gdzie $n \rightarrow \infty$. Przykładów ,stopniowalności kultur” $\mathrm{K}_{\mathrm{T}}$ i $\mathrm{K}_{\mathrm{W}}$ dostarcza materiał empiryczny, np. połączenia obrzędów pogrzebowych egipskiego i rzymskiego; czy przykład rodzimy: pomnik na placu Ignacego Paderewskiego w Reszlu ${ }^{14}$.

Czym jest $\mathrm{K}_{\mathrm{T}}$ ? Jak odróżnić $\mathrm{K}_{\mathrm{T}}$ od $\mathrm{K}_{\mathrm{W}}{ }^{\text {? }}{ }^{15}$ Kwestie te nie zostały dostatecznie wytłumaczone. Autor, proponując ten podział, odwołuje się do pierwotnego zachowania poznawczego człowieka, dla którego to, co znane, jest wartością odniesienia w poznawaniu tego, co

\footnotetext{
13 Tamże.

14 Pomnik ten powstał w roku $1905 \mathrm{w}$ celu upamiętnienia poległych w wojnie austriacko-pruskiej (1866) i francusko-pruskiej (1870-1871) mieszkańców Reszla i okolic. Pomnik stanowił obelisk z wyrytymi na nim nazwiskami poległych żołnierzy; na szczycie obelisku znajdował się posąg orła wzbijającego się do lotu. Po roku 1945 z obelisku zastąpiono orła dwoma mieczami, co nadało mu symbolikę grunwaldzką.

15 Por. R. Boroch, A Formal Concept of Culture in the Classification of Alfred L. Kroeber and Clyde Kluckhohn, „Analecta. Studia i Materiały z Dziejów Nauki” 2017, t. XXV, z. 2, s. 61-101; R. Boroch, Kultura w systematyce Alfreda L. Kroebera i Clyde'a Kluckhohna, Warszawa 2013.
} 
nieznane. To, w konsekwencji, prowadzi do subiektywnego i relatywnego tłumaczenia czy opisu zjawisk kultury, ponadto Autor przerzuca ciężar argumentacji na odbiorcę, który sam sobie wyjaśnia, subiektywnie i np. relatywnie, czym jest $\mathrm{K}_{\mathrm{W}}{ }^{16}$. Wyjaśnienie takie zależy od indywidualnego doświadczenia podmiotu oraz stopnia świadomości społeczno-socjologicznej w rozumieniu Charlesa W. Millsa ${ }^{17}$.

Bezsprzecznie WRO wymaga uzupełnienia faktograficznego. Na stronie 87 Autor pisze:

Weźmy za przykład los kobiety niezamężnej, która urodziła dziecko. Jeśli nie wsparła jej najbliższa rodzina (na to nie zawsze można było liczyć), nie miała z czego żyć. Przed stu laty nie było pracy dla kobiet i nie było sieci przedszkoli. Los i kobiety i jej nieślubnego dziecka był smutny. Nic dziwnego, że ówczesne obyczaje piętnowały zachodzenie w ciążę bez ślubu. Surowy obyczaj ochranial [wyróżnienie w oryginale - R. B.] młode kobiety przed zagrożeniem.

W przytoczonym fragmencie nie zostały podane żadne dane faktograficzne z takich dziedzin jak demografia historyczna, socjologia społeczna, etnologia czy historia XX wieku ${ }^{18}$. Zamiast tego Autor wygłosił własne poglądy (bądź potoczne opinie) na temat: kobiet niezamężnych rodzących dziecko, braku pracy dla kobiet oraz braku przedszkoli, a wszystko to luźno umiejscowił w czasie: ,przed stu laty” ${ }^{19}$.

Powyższy sposób argumentowania jest nie do zaakceptowania również z powodu zbytniej ogólnikowości. Autor ignoruje to, że sto lat temu, tak samo jak dziś, losy kobiet były zróżnicowane. Położenie kobiety za-

\footnotetext{
16 Powyższe błędy nazywa się po angielsku burden of proof fallacy oraz appeal to tradition fallacy. Określenie fallacy tłumaczy się na język polski jako sofizmat, jednakże może to być mylące, ponieważ sofizmat w języku polskim oznacza tyle, co rozumowanie pozornie poprawne, w którym umyślnie został ukryty błąd. W wypadku angielskiego określenia fallacy błąd nie jest ukryty rozmyślnie - jest niezmierzonym błędem w rozumowaniu. Innymi słowy nie ma tu mowy (chyba) o celowym wprowadzaniu czytelnika w błąd.

17 Por. Ch. W. Mills, The Sociological Imagination, Oxford 2000.

18 Można je znaleźć choćby w pracach: J. Kochanowski, Rewolucja międzypaździernikowa. Polska 1956-1957, Kraków 2017; J. Michalewicz, Elementy demografii historycznej. Materiały do wyktadów, ćwiczeń i metodyki prac badawczych, Warszawa 1979; J. S. Bystroń, Księga imion w Polsce używanych, Warszawa 1938; C. Kuklo, Demografia Rzeczypospolitej przedrozbiorowej, Warszawa 2009.
}

19 J. Stanisławek, dz. cyt., s. 86. 
leżało np. od jej statusu ekonomicznego, religii czy przynależności do określonych struktur (klas) społecznych ${ }^{20}$. Ponadto Autor zakłada, że w $\mathrm{K}_{\mathrm{T}}$ narodziny nieślubnego dziecka były rezultatem rozwiązłości obyczajowej - hedonizmu, przed którym $\mathrm{K}_{\mathrm{T}}$ ma kobietę chronić. Sąd ten jest zbyt mocny, ponieważ narodziny nieślubnych dzieci nie zawsze były rezultatem hedonizmu, lecz np. przemocy (agresji antropologicznej ${ }^{21}$ ). Autor nie uwzględnia np. tego, że ,przed stu laty” kobiety o niskim statusie ekonomiczno-społecznym były często zmuszane do „romansu”22. Nie precyzuje też, jakie kary społeczne były nakładane na kobiety z nieślubnymi dziećmi: nie uwzględnia problemu przemocy - jawnej i zakamuflowanej - wobec kobiet $\mathrm{i}$ ich nieślubnego potomstwa. Przykładem tej drugiej formy przemocy może być np. nadawanie nieślubnym dzieciom niespotykanych imion.

Podsumowując, proponowane $\mathrm{w}$ ramach WRO tezy są przykładem sofizmatu, który pozwolę sobie tu nazwać cock and bull story fallacy.

\subsubsection{Wartościowanie kultur}

Wartościowane $\mathrm{K}_{\mathrm{T}} \mathrm{i}_{\mathrm{W}}$ skutkuje powrotem do etnocentrycznego rozumienia zjawisk kultury. Przypomnijmy, że konsekwencją praktyczną etnocentrycznego ujęcia kultury jest konflikt antropologiczny ${ }^{23}$, który prowadzi m.in. do naukowego rasizmu, szowinizmu i nacjonalizmu,

\footnotetext{
20 Z tego względu, że dyskusja odbywa się na łamach czasopisma filozoficznego można tu odwołać się do przykładów z literatury pięknej. Sytuacja kobiet z tego okresu została przedstawiona np. w powieściach Zmartwychwstanie Lwa Tołstoja, Tessa d'Urberville Thomasa Hardy'ego czy w opowiadaniach Iwana Bunina.

${ }^{21}$ Por. R. Boroch, Agresja-wojna antropologiczna a nauki o kulturze - wielkie tematy kulturoznawstwa na marginesie krytycznej analizy dyskursu, „Kultura Bezpieczeństwa. Nauka-PraktykaRefleksje" 2016, nr 22, s. 81-94; A. Korzeniowska-Bihun, R. Boroch, Ukrainian Theatrical Projects as an Example of Anthropological Defence in Terms of Anthropology as Contemporary Social Warefare, „Security Dimensions. International \& National Studies” 2017, No 24, s. 122-136.

22 Literackim obrazem tego problemu niech będzie powieść Jean Rhys Wide Sargasso Sea.

23 Por. np. R. Boroch: Agresja-wojna antropologiczna a nauki o kulturze - wielkie tematy kulturoznawstwa na marginesie krytycznej analizy dyskursu, „Kultura Bezpieczeństwa. Nauka-Praktyka-Refleksje" 2016, nr 22, s. 81-94; R. Boroch, Wywiad antropologiczny-przyczynek do antropologii stosowanej, „Bezpieczeństwo. Obronność. Socjologia” 2016, nr 3(5), s. 5-18.
} 
a wreszcie do wykluczenia lub zniszczenia wykluczonych struktur społecznych, których kulturę ( $\mathrm{w}$ tym wypadku $\mathrm{K}_{\mathrm{w}}$ ) uznaje się za gorszą ${ }^{24}$.

Określenie kultura oznacza sferę zjawisk ocenianych pozytywnie, przede wszystkim takich, które są pożądane przez elity społeczne. W ujęciu WRO zjawiskami pożądanymi są te, które reprezentuje kultura tradycyjna $-\mathrm{K}_{\mathrm{T}}$.

Można uznać, że WRO jest próbą teoretycznej obrony $\mathrm{K}_{\mathrm{T}}$, którą - jak się wydaje - jest dla Autora kultura rodzima, przed kulturą napływową - $\mathrm{K}_{\mathrm{w}}$. Jednakże wprowadzona aksjologia kultury jest w tym wypadku problematyczna, gdyż Autor nie wymienia przykładowych pozytywnych zjawisk kultury $\mathrm{K}_{\mathrm{T}}$. Zamiast tego WRO wprowadza kategorię negatywną - $\mathrm{K}_{\mathrm{W}}$-jako przeciwieństwo tego, co pozytywne, wyróżniające i pożądane (bez konieczności nazywania). W konsekwencji prowadzi to do ogólnikowych konkluzji odnośnie do ideałów, którym Autor przeciwstawia nieideał; nie odsyła także czytelnika do żadnych przykładów (zob. [1]-[4] punkt 1). W tym wypadku oczywistym jest pytanie o zasadność przypisania kulturom $\mathrm{K}_{\mathrm{T}}$ i $\mathrm{K}_{\mathrm{W}}$ cech zachodnioeuropejskich na zasadzie ich rozłączności, tj. $\mathrm{K}_{\mathrm{T} \text { (elitaryzm, idealizm, ascetyzm) }}$ Vs. $\mathrm{K}_{\mathrm{W} \text { (egalitaryzm, utylitaryzm, hedonizm) }}$ ? Dlaczego nie cech typowo polskich, takich np. jak lojalizm, irredentyzm, ugodowość itd. ${ }^{25}$ ? Czy propozycję cech $\mathrm{K}_{\mathrm{T}}$ i $\mathrm{K}_{\mathrm{W}}$ można tłumaczyć nawiązaniem do szczególnie rozumianej tradycji wieku oświecenia?

\footnotetext{
24 Przypomnę, że każda etnocentryczna doktryna kultury jest normatywna. Natomiast implementacja owej normatywności ma charakter konfliktu, zmusza do porzucenia czegoś na rzecz czegoś innego. Potocznie uważa się, że bardziej agresywne antropologicznie struktury społeczne to takie, które są lepiej zorganizowane np. w zakresie procesu decyzyjnego. De facto nie chodzi o zaawansowanie pod względem efektywności procesu decyzyjnego ani organizację konkretnej struktury społecznej, lecz o antropologiczną odporność na ideologiczną asymilację. Odporność antropologiczna bezpośrednio przekłada się na jakość kapitału ludzkiego, ocenianego pod względem inwencji, kreatywności, świadomości społecznej (w rozumieniu Émile’a Durkheima i szerzej w ujęciu Charlesa Wrighta Millsa), pierwszeństwa obywatelskości nad narodowością itd. Więcej na ten temat zob. K. Booth, Strategy and Ethnocentrism, New York 2017; Ch. W. Mills, The Sociological Imagination, Oxford 2000.

25 Za T. Chińciński, Polska myśl liberalna XIX wieku. Rozważania o książce Macieja Janowskiego „Polska myśl liberalna do 1918 roku”, „Czasy Nowożytne” 2000, t. VIII-IX, s. 305-316.
} 


\section{Podsumowanie}

Przypomnę, cechami $\mathrm{K}_{\mathrm{T}}$ i $\mathrm{K}_{\mathrm{W}}$ są:

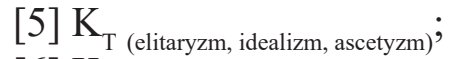

[6] $\mathrm{K}_{\mathrm{W} \text { (egalitaryzm, utylitaryzm, hedonizm) }}{ }^{26}$.

Zostaje także wyznaczona cezura - początek WRO zbiega się z pojawieniem się artefaktów:

[7] Pojawienie się prądu muzycznego o nazwie „rock and roll”.

[8] Pojawienie się na plażach atlantyckich ludzi ubranych w kąpielowy strój o nazwie bikini.

Cechy [5] i [6] zostały podzielone dychotomicznie. Rodzi to dwa problemy. Pierwszym jest problem epistemologiczny; opisywanie zjawisk kultury dychotomicznie jest opisywaniem skrajności - w rozumieniu Aarona T. Becka - co eliminuje stany przejściowe zmian np. strukturalnych czy jakościowych. Zmiany takie zawsze są homeomorficzne. Drugi problem jest analityczny, np.: (1) cechy $\mathrm{K}_{\mathrm{T}}$ i $\mathrm{K}_{\mathrm{W}}$ mogą być poszerzone o inne; (2) dychotomiczny podział nie oddaje w swoim opisie złożoności i dynamiczności zmian w kulturze ${ }^{27}$; (3) pomija to, co nie posiada skrajności - np. tożsamość albo narodowość; (4) jakie są kryteria przypisania cech, np. $\mathrm{K}_{\mathrm{T}}$ przypisano cechę ,asceza"28.

Interesującym przedmiotem rozpatrywań obok WRO powinny być także podmioty kulturę stwarzające. Jak to należy rozumieć? Chodzi tu o to, kto jest zarządcą kultury, kto inicjuje i kontroluje zmiany społeczno-kulturowe, itd., innymi słowy chodzi tu o faktycznego posiadacza kultury $^{29}$. Przykładem takiego zarządzania jest polityka społeczna Wielkiej

\footnotetext{
26 Według przypisu 2., zawartego w artykule Stanisławka, wyznaczniki $\mathrm{K}_{\mathrm{T}}$ zostały podane za Bogusławem Wolniewiczem, jednakże brak adresu bibliograficznego uniemożliwia weryfikację. Jeżeli jednak przyjmiemy, że prawdą jest to, że taki podział do badań zjawisk kultury proponuje B. Wolniewicz, to propozycja taka jest oderwana od rzeczywistego kontekstu zjawisk kulturowych; należy ją uznać za propozycję teoretyczną.

27 Por. A. Nobis, Zmiana kulturowa. Między historia i ewolucją, Wrocław 2006.

28 Dlaczego ,asceza”? Uzasadnienie może być np. religijne (asceza w chrześcijaństwie); jeżeli akceptujemy uzasadnienie religijne, to czy fascynację buddyzmem obecną w kulturze zachodniej od lat 50. XX wieku (buddyjska „droga środka” jest przecież przykładem i zachętą do ascetycznego życia) zaliczymy do $\mathrm{K}_{\mathrm{W}}$ czy $\mathrm{K}_{\mathrm{T}}$ ? Przypomnę, że lata 50. XX zostały wyznaczone jako cezura WRO.

29 Posiadacz kultury narzuca innym swoją interpretację rzeczywistości, system wartości, itd.
} 
Brytanii w Indiach Brytyjskich (ang. British Raj) w latach 1858-1947. Innymi słowy, nie chodzi tu o to, jaka jest $\mathrm{K}_{\mathrm{T}}$ czy $\mathrm{K}_{\mathrm{W}}$, lecz czyja jest $\mathrm{K}_{\mathrm{T}}$ czy $\mathrm{K}_{\mathrm{W}}$ - kto nią zarządza? W tym też kontekście adekwatnym pytaniem jest pytanie np. o charakter i funkcję podmiotu kulturotwórczego oraz strategicznego planowanego kierunku zmian społecznych, sposobu ich implementacji i konsekwencji implementowania np. dialog czy wojna antropologiczna.

Tezy WRO, sugerujące wartościowanie kultur, wprowadzają oczywiste przeciwieństwa: kultura - cywilizacja; kultura materialna - kultura niematerialna (duchowa); kultura wysoka - kultura niska itd..$^{30}$ Podstawą teoretyczną tych rozważań jest założenie, że silne społeczeństwa mogą oprzeć się czynnikom napływowym niosącym ze sobą zmiany ${ }^{31}$. W tym też sensie WRO może być przykładem normatywnej teorii ochronnej, której celem jest intelektualna indoktrynacja i zapobieganie zmianom. W tym też kontekście WRO mogłaby być podstawą rozważań w ramach filozofii bezpieczeństwa kultury - kultura bezpieczeństwa i bezpieczeństwo kultury.

\section{Uzupelnienie kontekstowe WRO - od etnocentryzmu do agresji antropologicznej}

Określenie „etnocentryzm” jest używane w znaczeniu ${ }^{32}$ : (1) centralności i wyższości konkretnej struktury społecznej - w tym kontekście termin ten został wprowadzony przez Williama G. Sumnera w roku $1906^{33}$; (2) jako termin specjalistyczny w metodologii nauk społecznych - w praktyce oznacza, że badacz dokonuje transmisji systemu wartości kultury własnej (którą uznaje za lepszą) na system wartości kultury innej; (3) jako synonim zdeterminowania przez własną kulturę (ang. culture-bo-

\footnotetext{
30 Por. K. Żygulski, Wstęp do zagadnień kultury, Warszawa 1972; S. Piekarczyk, Historia, kultura, poznanie, Warszawa 1972; A. Kłoskowska, Społeczne ramy kultury, Warszawa 1972; M. Czerwiński, Kultura i jej badanie, Wrocław-Kraków-Warszawa 1971.

31 Por. np. P. Bourdieu, Cultural Reproduction and Social Reproduction (1977).

32 Propozycje zawarte w punktach (1)-(3) za: K. Booth, Strategy and Ethnocentrism, New York 2017.

33 Por. W. G. Sumner, Folkways, Boston 1906, s. 13. (za K. Booth, dz. cyt.).
} 
und) - odnosi się do niemożność oceny aktualnej rzeczywistości z punktu widzenia innej grupy etnicznej lub narodowości.

Przypomnę, badania nad etnocentryzmem eksplorują dwa wymiary. Pierwszym jest historia etnocentryzmu, drugim zaś - przyczyny i rozwój postaw i poglądów etnocentrycznych w aktualnych i konkretnych strukturach społecznych (etnicznych czy narodowych).

Powyższe ujęcia wpisują się w szeroki kontekst badań społecznych, m.in. badania nad postawami ksenofobicznymi (a szerzej bezpieczeństwem kultury i kulturą bezpieczeństwa) ${ }^{34}$, które są prowadzone w ramach takich dyscyplin jak antropologia stosowana, etyka stosowana, planowanie strukturalno-strategiczne, historia wojskowości (zwłaszcza w kontekście polityczno-wojskowym), czy też teoria kultury. Wszystkie wymienione dziedziny rozwijają się teoriopoznawczo, lecz z silnym naciskiem na ich możliwości aplikacyjne. Aplikacyjność badań w zakresie etnocentryzmu będzie polegała na jego ukierunkowywaniu oraz kontrolowaniu zmian strukturalnych, które przybierają często formę agresji antropologicznej, a w skrajnych przypadkach - wojny antropologicznej. Prowadzi to bezpośrednio to prób stworzenia superkultury, w ramach której każdy obszar życia ludzkiego byłby ustandaryzowany. Podejmowanie takich prób jest typowe dla względnie izolowanych struktur społecznych. Ideę superkultury upodobały sobie wszelkiego rodzaju ujęcia normatywne, które postulują standaryzację, nie bacząc, że wiąże się to ze zmuszaniem człowieka do zrzeczenia się poczucia niezależności i odrębności osobistej w imię dobra wspólnego - etnicznego lub narodowego. W rzeczywistości indywidualizm człowieka jest wartością niezbywalną, innymi słowy: nie można się go zrzec. Indywidualizm, gdy jest zagrożony, przybiera formy ukryte, co jest przejawem tzw. obrony antropologicznej i - kulturowego oszustwa - które polega na ukrywaniu tego co różne, indywidualne, kreatywne itd. (zob. kontinuum kulturowe punkt 1.2.1.). Innymi słowy, superkultura, która w koncepcji Stanisławka ukrywa się pod nazwą kultury tradycyjnej - $\left(\mathrm{K}_{\mathrm{T}}\right)$ - jest formą przymusu, czyli agresji antropologicznej.

34 Por. J. Błahut-Prusik, Pomiędzy definicją bezpieczeństwa a możliwościa jego urzeczywistnienia, czyli ku wiecznemu niespetnieniu?, „Humanistyka i Przyrodoznawstwo” 2012, t. 18, s. $203-$ 212. 
Opracowanie kontekstu interpretacyjnego, np. społeczno-historycznego, opiera się na imitowaniu jego prawdziwości (ang. fake data). Innymi słowy polega na wprowadzeniu do dyskursu struktury dezinformacyjnej: powszechnie rozpoznawalne zjawiska kultury (np. rock and roll i bikini) zostają umieszczone w kontekście dezinformacyjnym, który skonstruowany jest zarówno z sądów bezsprzecznie prawdziwych, jak i takich, które są prawdziwe pod pewnym warunkiem, np. są prawdziwe w przekonaniu kogoś, kto wierzy (z jakiegoś powodu), że są one prawdziwe. Nastawienie odbiorcy na treści, które chce on (za wszelką cenę) usłyszeć nazywa się postawą dogmatyczną odbiorcy. Rozpoznanie właściwej postawy dogmatycznej odbiorcy pozwala twórcy dezinformacyjnego kontekstu interpretacyjnego na opracowanie go w taki sposób, by spełniał warunki: aktualności - uwzględniał problemy ważne z punktu widzenia odbiorcy; racjonalności - pozbawiony był niedorzeczności; spójności - był koherentny logicznie; quasi-prawdziwości - zawieral treści zgodne z postawą dogmatyczną odbiorcy. W celu spełnienia powyższych warunków twórca dezinformacyjnego kontekstu interpretacyjnego przyjmuje strategię polegająca na przeplataniu tego, co zgodne z postawą dogmatyczną odbiorcy, z tym co z postawą dogmatyczną odbiorcy jest niezgodne. Tak przygotowane treści odbiorca konfrontuje ze swoim światopoglądem (np. konfrontuje to, co nieznane, z tym, co znane) i poddaje wartościowaniu (np. porównując to, co utrwalone w pamięci społecznej, $\mathrm{z}$ tym, co utrwalone nie jest). Wszystkie te mechanizmy wykorzystywane są przez szeroko rozumianą politykę dezinformacji społecznej. Współcześnie dezinformacja społeczna jest wielowymiarowa, ponieważ jej właściwa struktura semantyczna jest rozproszona w siatce kanałów komunikacyjnych takich jak prasa, radio, telewizja, Internet, bilbordy, ikonografia, agitatorzy ${ }^{35} \mathrm{i}$ instytucje rządowe lub pozarządowe itd. Organizację semantyczno-semiotyczną w wielowymiarowych środowisku komunikacyjnym nazywa się „dyskursem”. Dyskurs może być sterowany. Wyróżnia się tu dwa poziomy sterowania: poziom człowieka i poziom maszyny. Pozio-

\footnotetext{
35 Więcej o roli agitatorów-liderów: R. Boroch, M. Chmielecka, Przywództwo w świetle etyki stosowanej - zastosowanie coachingu w procesie ksztatcenia liderów (przywódców), „Teraźniejszość - Człowiek - Edukacja" 2017, t. 20, nr 3(79), s. 35-46.
} 
my sterowania tworzą trzy uniwersa interakcji: (1) człowiek $\leftrightarrow$ człowiek; (2) człowiek $\leftrightarrow$ maszyna; (3) maszyna $\leftrightarrow$ maszyna. Przedmiotem zainteresowania nauk społecznych są wszystkie trzy uniwersa, ich wzajemne relacje, złożoności strukturalne i wpływ na struktury społeczne. Z punktu widzenia dezinformacji najważniejszy jest wpływ na struktury społeczne, ponieważ formułując $w$ ramach dyskursu pytanie i je rozpowszechniając, nie poszukuje się odpowiedzi na nie, ale się tę odpowiedź projektuje, uruchamiając procesy idealizacyjne i mitologizacyjne ${ }^{36}$. Idealizacja to próba wpływania na postawę dogmatyczną odbiorcy, czyli na jego nastawienie do zjawisk kultury. Mitologizacja zaś jest procesem wtórnym, w trakcie którego odbiorca nie mający dostatecznej wiedzy specjalistycznej na temat określonego zjawiska kultury konstruuje na własny użytek jego wyjaśnienie. Mitologizacja jest wykorzystywana przez twórców dyskursu do utrwalania postawy dogmatycznej odbiorcy, który sam przecież dostarczył budulca do konstruowania określonego mitologemu czy narracji. Idealizacja i mitologizacja są wyznaczone przez paradygmat mody. Moda to „szczególna popularność”, która jest utrwalona, rozpowszechniona i uprawdopodobniona jako wzór do naśladowania ${ }^{37}$. Ten ostatni element

\footnotetext{
36 Por. Ch. Cross, Explanation and the theory of question (1991); A. Ram, A theory of question and question asking (1991); A. Brożek, Theory of Questions. Erotetics Through the Prism of Its Philosophical Background and Practical Applications (2011), https://doi.org/10.1163/9789401207324.

37 Problem mody w naukach społecznych jest zjawiskiem złożonym. Dla wyjaśnienia tej złożoności posłużę się dwoma przykładami: (I) wpływem Franza Boasa na amerykańską antropologię; oraz znaczeniem, jakie na badania antropologiczne wywarł tzw. (II) dogmat chicagowski. W wypadku (I) mamy do czynienia z wpływami Boasa oraz jego bezpośrednich uczniów w instytucjach akademickich (przyznawanie stypendiów, decyzje o kierunku badań itd.). Dogmatyczne przyjmowanie teorii Boasa doprowadziło do zaistnienia w akademii trzeciej fali badań - „neoboasianizm” - co obecnie nazywa się ,antropologią naiwną”. Przykładem antropologii naiwnej jest dogmat chicagowski. Warto przypomnieć kilka faktów: pierwsza praca doktorska w USA z antropologii została obroniona w roku 1892 przez Alexandra Francisa Chamberlina a jej promotorem był Boas. W roku 1894 istniało 13 instytucji akademickich oferujących zajęcia lub studia z zakresu antropologii; w latach 1940-1941 było ich już 167. W roku 1899 Boas obejmuje stanowisko profesora antropologii na Uniwersytecie w Columbia; absolwenci Boasa w roku 1950 to 94 tytularnych profesorów antropologii oraz 59 tytularnych profesorów innych dyscyplin. Konkludując, dominacja Boasowskiego paradygmatu badań w wydaniu jego uczniów doprowadziła z jednej strony do poznawczego zastoju (w konsekwencji regresu), z drugiej zaś do wątpliwych etycznie postaw samych badaczy, którzy w machinie akademickiego awansu przyjmowali niewłaściwe praktyki np. pan-boasianizm - wszelkie analizy rozpoczyna się od reinterpretacji teorii Boasa oraz pomija się to, co niespójne z teorią. Por. E. Voegelin, Anthropology in American Universities, „American
} 
jest kluczowy, ponieważ wpisuje się w naturę człowieka, zwłaszcza jego zdolności mimetyczne ${ }^{38}$.

Idealizacja i mitologizacja prowadzą nieuchronnie do konfliktu, który w literaturze przedmiotu nazywa się wojną kultur ${ }^{39}$. Wojna kultur przybiera formy agresji antropologicznej. Pojęcie agresji antropologicznej stosuje się, analizując (1) antropopresję, czyli wpływ człowieka na środowisko naturalne, oraz (2) socjopresję (presję społeczną), czyli nacisk środowiska społecznego na indywiduum i mniejsze struktury społeczne. Tym pierwszym zjawiskiem zajmują się m.in. badacze ewolucji kultury, tym drugim zaś - semiotyka antropologiczna. W wypadku WRO będzie nas interesować socjopresja, zwłaszcza w kontekście oszustwa kulturowego, które jest formą oporu lub obrony przed agresją antropologiczną.

Formy oporu (także kooperacji) dzieli się na aktywne i bierne. O oporze aktywnym mówimy wtedy, gdy przeciwstawiamy się czemuś podejmując konkretne działania, ponieważ istnieje realna możliwość, że w wyniku agresji antropologicznej utracona zostanie ważna dla nas wartość (dobro). O oporze biernym mówimy zaś wtedy, gdy przeciwstawiamy się czemuś, nie podejmując żadnych działań tak długo, dopóki nie zostaniemy sprowokowani zakresem agresji antropologicznej, która wzbudzi w nas realną obawę odnośnie do utraty ważnej dla nas wartości (dobra). Wartość (dobro) musi w tym wypadku być utrwalona w świadomości społecznej; podejmując jakiekolwiek działania, człowiek indywidualny działa w wierze, że czyni słusznie i dla dobra własnego, i społecznego (grupy). Podział na formy aktywne i bierne opiera się na kryterium oddalenia generacyjnego (oddalenie pokoleniowe). Zwróćmy w tym miejscu uwagę, że oddalenie generacyjne jest czynnikiem wpływającym na

Anthropologist. New Series" 1950, vol. 52, no. 3, pp. 350-391; E. Leach, Review of Man's Glassy Essence: explorations in semiotic anthropology, „American Ethnologist” 1985, no. 12, s. 154-156, https://doi.org/10.1525/ae.1985.12.1.02a00130.

38 Pojęcie mimesis jest dyskutowane w ramach wielu dyscyplin, np.: literaturoznawstwo, estetyka, semiotyka, psychologia czy biologia ewolucyjna.

39 Wojna kultur jest terminem ukutym przez J. D. Huntera (por. Culture Wars: The Struggle to Define America, Basic Books 1991). Termin ten odnosi się do amerykańskiego konfliktu między konserwatywnymi a liberalnymi wizjami rzeczywistości; w tym kontekście „wojna” jest określeniem metaforycznym odnoszącym się do zmagań ideologicznych w instytucjach rządowych i społecznych. 
osłabienie zaangażowania indywidualnego oraz kooperację wewnątrz struktury społecznej w celu osiągnięcia określonych celów. Im większa wartość oddalenia generacyjnego, tym większa wartość dezinformacyjna (większa redundancja informacyjna).

Oddalenie generacyjne często porównuje się do łańcucha referencyjnego lub siatki. Porównanie to jest problematyczne, ponieważ w wypadku zjawisk kultury trudno jest jednoznacznie wskazać na przyczyny ich powstania. Nie jest też możliwe określenie tzw. momentu granicznego, czyli takiego, który stanowi koniec jednego zjawiska kulturowego i początek nowego. Dotyczy to także WRO - jej moment graniczny także nie może być jednoznacznie określony. Wskazywanie na pojawienie się rock and rolla i bikini (w Europie Zachodniej) jest nieprecyzyjne. Nie chodzi tu bynajmniej o podanie konkretnej daty, lecz o wskazanie szerszego kontekstu społecznego. Rock and roll oraz bikini to artefakty powszechnie znane, czyli rozpowszechnione i rozpoznawalne. Informacje odnoszące się do tych artefaktów są rozproszone w wi elow y mi a row y m środow is ku komunikacyjnym konkretnych struktur społecznych, co silnie wpływa na postawę dogmatyczną odbiorcy. Poza tym każdy z tych artefaktów należy do innego systemu semiotyczno-semantycznego. Elementem wspólnym jest to, co nazywa się w kontekście semiotycznym znak-nośnik (ang. sign-vehicle), któremu przypisywane są różne znaczenia w wymiarze pokoleniowym (wymiar poziomy struktury społecznej) oraz międzypokoleniowym (wymiar pionowy struktury społecznej). Innymi słowy, w ramach wymiaru poziomego i pionowego mimo tożsamości semiotycznej różna jest semantyka rock and rolla i bikini.

Połączenie wymiaru poziomego i pionowego nazywa się ,parantelami semiotyczno-semantycznymi”. Parantele są obszarem „mediacji semantycznej", która jest inicjowana w kolejnych etapach: (1) re je s trow a nia obiektu i jego wyróżników; (2) a nalizowania składników wyróżników obiektu; (3) in d e k s o w a n i a wyróżników obiektu; (4) „s y g n a t u r o w a n i u” wyróżników obiektu. Etapy (1)-(4) (dalej RAIS) inicjują semantyzację obiektu jako złożonej, całościowej struktury (ang. complex-entity). Przez semantyzację obiektu należy rozumieć proces łączenia rozporoszonych $\mathrm{w}$ wielowymiarowej przestrzeni komunikacyjnej 
depozytów semantycznych. Innymi słowy, człowiek indywidualny może de facto nigdy nie zetknąc się z rock and rollem albo bikini, a mimo to mieć opinię na temat ludzi, którzy takimi artefaktami się posługują np. na temat ich świata wartości. Przykładowe artefakty w tym wypadku pełnią funkcję symboli - wywoływaczy semantycznych.

RAIS jest etapem wstępnego poznawania oraz konstruowania reprezentacji wiedzy, która służy jako wartość odniesienia w procesie porównywania znanego systemu semiotyczno-semantycznego z nowo poznawanym. To, co odmienne od znanego systemu semiotyczno-semantycznego, jest anomalią, której poznawanie odbywa się poprzez jej porównanie $\mathrm{z}$ tym, co regularne (powtarzalne). W praktyce anomalie otwierają możliwość opisu własności nowo poznawanych systemów semiotycznosemantycznych, co pozwala na ustalenie warunków koniecznych ich występowania. Poważny problemem w opisie zjawisk kultury stanowią opisane przez J. Łotmana antynomie semiotyki kultury, od których WRO nie jest wolne:

- jądro - peryferie - relacje centrum - peryferie, gdzie centrum jest elementem sztywnym, a peryferie elementem walencyjnym ${ }^{40}$;

- systemowe - niesystemowe - opisy koncentrują się na tym, co systemowe, pozostawiając to, co niesystemowe, poza obszarem swoich badańn ${ }^{41}$;

- jednoznaczne - ambiwalentne - system nie jest do końca uporządkowany, czyli istnieje wewnętrzna ambiwalencja ${ }^{42}$;

- opisane - nieopisane - każde zjawisko staje się realnością społeczną od momentu jego opisu. Sam fakt opisu podwyższa zorganizowanie i przez to obniża dynamikę systemu ${ }^{43}$;

- konieczne - zbyteczne - w kulturze istnieją systemy znakowe nastawione na relewancję bądź redundancję ${ }^{44}$.

\footnotetext{
40 J. Łotman, Uniwersum umystu. Semiotyczna teoria kultury, przeł. B. Żyłko, Gdańsk 2008, s. 35 .

$41 \quad$ Tamże, s. 33-34.

42 Tamże, s. 34-35.

43 Tamże, s. 35.

44 Tamże, s. 36.
} 
Konkludując. W każdej kulturze istnieje „element tradycyjny” - centrum/jądro (coś, co jest wiadome) i „element współczesny” - peryferie/ płaszcz jądra (coś, co jest nieznane).

Powyższa konkluzja dotyczy wszystkich wymienionych wyżej antynomii, tzn. w każdej kulturze istnieją obiekty systemowe i niesystemowe, jednoznaczne i ambiwalentne, opisywalne i nieopisywalne, konieczne i zbyteczne.

\section{$* * *$}

Podsumowaniem niniejszego paragrafu niech będzie kilka twierdzeń przyjmowanych w antropologiczno-semiotycznym rozumieniu kultury ${ }^{45}$.

[9] Wzrost wartości redundancji następuje wraz ze wzrostem wartości oddalenia generacyjnego (ilości pokoleń).

[10] Wartość odniesienia (czyli znany kontekst interpretacyjny) zachowuje koherencję jedynie w ramach jednej struktury społecznej: pionowej albo poziomej.

[10a] Zmiana jakościowa lub ilościowa struktury społecznej koherencję zakłóca.

[10b] Celem agresji antropologicznej jest zakłócenie lub zerwanie koherencji pionowej lub poziomej struktury społecznej.

[11] Parantele to obszar mediacji semantycznej.

[12] Depozyty semantyczne artefaktów $X$ są rozporoszone w wielowymiarowej przestrzeń komunikacyjnej, które spaja proces RAIS.

[13] Proces RAIS rozumie się jako proces: (1) rejestrowania obiektu i jego wyróżników; (2) analizowania składników wyróżników obiektu; (3) indeksowania wyróżników obiektu; (4) „sygnaturowaniu” wyróżników obiektu.

[13a] Zjawisko $x$ istnieje w czasie $t$ w kontinuum społecznym $s^{t}$.

[13b] Zjawisko $x$ jest możliwe do opisu w postaci deskrypcji $d$ określonych.

45 Por. R. Boroch, Rethinking Milton Singer's Semiotic Anthropology: A Reconnaissance, „Semiotica" 2018, Vol. 224; doi:10.1515/sem-2016-0119, URL: <https:/www.degruyter.com/view/j/ semi.ahead-of-print/sem-2016-0119/sem-2016-0119.xml?format=INT>, https://doi.org/10.1515/ sem-2016-0119. 
[13c] W czasie $t$ deskrypcje $d$ zjawiska $x$ s ą utrwalan e i rozpowszechniane w dziedzinie kontinuum społecznego $s^{t}$.

$$
F\left(x, t, s^{t}, d\right)
$$

\section{Uzupelnienie faktograficzne WRO}

\subsection{Uwagi techniczne}

Początek WRO jest wyznaczony pojawieniem się rock and rolla oraz kostiumu kąpielowego bikini w latach 50. XX wieku w krajach Zacho$\mathrm{du}^{46}$ :

Przez współczesną rewolucję aksjologiczno-obyczajową (w skrócie: współczesną rewolucję obyczajową) rozumiemy przemiany w obszarze wartości oraz w obyczajach, jakie zachodzą od lat pięćdziesiątych w krajach Zachodu. Ich początek wyznacza pojawienie się rock and rolla oraz kostiumu bikini na plażach Atlantyku ${ }^{47}$.

W celu usprawnienia dyskusji będę posługiwał się równoważnikami: [14] Pojawienie się prądu muzycznego o nazwie rock and roll.

[15] Pojawienie się na plażach atlantyckich ludzi ubranych w kąpielowy strój o nazwie bikini.

Równoważniki [14] i [15] zostały sformułowane bez uwzględnienia szerszego kontekstu np. antropologiczno-historycznego, co postaram się pokrótce uzupełnić $\mathrm{w}$ kolejnym punkcie na podstawie literatury przedmiotu. Odnośnie do tezy [14] będę opierał się na pracy E. Warda The History of Rock and Roll ${ }^{48}$, odnośnie zaś do tezy [15] - na monografii P. Alaca Bikini Story ${ }^{49}$. Pozostałe źródła podaję w przypisach dolnych.

\subsection{Muzyka - rock and roll ${ }^{50}$}

Rock and roll został rozpropagowany w Wielkiej Brytanii przez Billa Haleya, którego płyty były dostępne szerszej publiczności i cieszyły się

\footnotetext{
$46 \quad$ J. Stanisławek, dz. cyt., s.85. W przypisie $1 \mathrm{w}$ artykule Stanisławka podana jest tylko informacja, że kostium kąpielowy bikini pojawił się w roku 1946 na pokazie mody.

47 Uwzględniając geograficzny rozmiar Atlantyku stwierdzenie „,na plażach Atlantyku” jest problematyczne, podobnie jak ograniczenie: „kraje Zachodu” - kryterium to jest uzależnione od przyjętego kontekstu, np. historycznego, religijnego czy politycznego.

48 E. Ward, The History of Rock and Roll, Kindle Edition: Flatiron Books 2016.

49 P. Alac, Bikini Story, Kindle Edition: Parkstone International 2015.

50 Historia rock and rolla to historia kultury Stanów Zjednoczonych, fenomenalny przykład
} 
powodzeniem, mimo że BBC nie udostępniało jego utworom wiele czasu antenowego. Sytuacja zmieniła się w 1955 roku po premierze filmu The Blackboard Jungle (reż. R. Brooks). Film ten zapoczątkował „erę buntu dla buntu", której symbolem stał się właśnie rock and roll (zwłaszcza piosenka pt. Rock around the Clock, Bill Haley \& His Comets $)^{51}$. Do promocji rock and rolla w Wielkiej Brytanii przyczyniło się także sprytne posunięcie gitarzysty T. W. Hicksa i fotografa J. Kennedy'ego, którzy postanowili wykorzystać dobrze sprzedające się tabloidy w celu rozpropagowania „rockandrollowego stylu życia”. Przy okazji chcieli też zdystansować się od rasistowskich ekscesów, z którymi rock and roll był kojarzony za sprawą subkultury Teddy Boy ${ }^{52}$. Hicks zmienił nazwisko na Steel (nazwisko przejęte po jego dziadku; wskutek pomyłki Decca Records utrwaliła się grafia Steele). Dnia 16 września 1956 roku została opublikowana w magazynie „The People” (ok. 4,5 miliona czytelników) fotografia Tommy’ego

wpływania na siebie kultur różnych grup etnicznych, prowadzącego do wytworzenia zjawiska transkulturowego raczej niż interkulturowego. Historia ta zaczyna się w połowie XIX wieku, gdy wśród Afroamerykanów rozpowszechniony był zwyczaj grupowego śpiewania podczas pracy czy w czasie odpoczynku. Pieśni były wyrazem jedności członków takiej grupy, ale także niosły głębszy przekaz historyczny - utrwalały niedole niewolniczego życia. W podobny sposób wykorzystywały muzykę białe wiejskie społeczności. John Wesley Work III, badacz afroamerykańskiego folkloru nagrał w latach $30 \mathrm{XX}$ wieku w Fort Valley (Georgia) kilka piosenek, które były wykonywane z akompaniamentem muzycznym (instrumenty szarpane) przez najstarszych członków lokalnej afroamerykańskiej społeczności. Były one zdumiewająco podobne do muzyki wykonywanej przez białe zespoły (ang. white string-band music) Warto dodać, że w latach $20 \mathrm{XX}$ wieku istniały zespoły złożone zarówno z białych, jak i czarnych muzyków-amatorów (ang. biracial bands).

51 Akcja filmu rozgrywa się w North Manual Trades High School, wielorasowej szkole miejskiej. Pracę w tej szkole podejmuje nowy nauczyciel Richard Dadier (grany przez Glenna Forda), który stara się zainteresować nauką uczniów, którym przewodzi Gregory Miller (grany przez Sidney'a Poitiera) i którzy demonstrują niejednokrotnie antyspołeczne zachowania. Film spotkał się z dużym zainteresowaniem widzów i jak na tamte czasy przyniósł spore zyski (ponad 4 miliony dolarów).

52 Subkultura określana nazwą Teddy Boy rozpoczyna pokoleniową zmianę światopoglądową nie tylko w zakresie mody (Teddy Boy oraz Teddy Girl) ale i ideologii, propagując hasła ksenofobiczne. Przypomnę, że subkultura Teddy Boy była powiązana z białą klasą pracującą i bliska ruchowi Union Movement Oswalda Mosley'a i White Defence Language. W 1958 wybuchły w Notting Hill zamieszki przeciwko lokalnej ludności pochodzenia hinduskiego. Reakcja władz na wydarzenia w Nothing Hill była ostra i zdecydowana; policja aresztowała 140 demonstrantów, 9 młodocianych skazano na karę 5 lat więzienia oraz grzywny w wysokości 500 funtów (dla porównania - średnie tygodniowe wynagrodzenie w roku 1950 wynosiło 7,28 funtów; w roku 1954 samochód Mini kosztował 496 funtów). 
Steele'a z grupa dziewcząt opatrzona tytułem ,Rock and roll has got the debs, too!'. Fotografia przedstawiała pierwsze rockandrollowe przyjęcie w Londynie, które rozpoczęło się o 8 wieczorem i zakończyło o świcie. Intryga ta rozpoczęła karierę muzyczną Steele'a w Decca Record (Rock Around the Town, 12 października 1956, 13 miejsce na liście przebojów) oraz rozpropagowała „rockandrollowy styl życia” wśród brytyjskich nastolatków.

Ponadto, do rockandrollowej rewolucji w Europie Zachodniej przyczyniły się także zmiany społeczne w XIX i XX wieku w Stanach Zjednoczonych, w tym rozwój show-biznesu ${ }^{53}$ oraz przemysłu płytowego, który bezpośrednio wpłynął na kształtowanie się gatunków muzycznych, oraz

53 W Stanach Zjednoczonych połowy XIX wieku nie istniał show-biznes. Sztuka przeznaczona dla klasy średniej i wyższej była niedostępna dla biedoty z regionów rolniczych. Ani białych, ani czarnych robotników rolnych nie było stać na to, by np. obejrzeć występy Fisk Jubillee Singers (Afroamerykański zespół a cappella powstał w roku 1871. Pieśń Swing Low, Sweet Chariot w roku 2002 została dodana do National Recording Registory w roku 2008; Fisk Jubillee Singers odznaczono medalem National Medal of Arts). Koncerty tego zespołu odbywały się zazwyczaj w dużych miastach. Członkowie wspólnot rolniczych tamtego okresu z racji ograniczeń ekonomicznych prowadzili „osiadły tryb życia” - podróż do miasta leżała zwykle poza zasięgiem ich możliwości finansowych. Powstawała więc muzyka - w polskim kontekście określilibyśmy jako muzykę ludową - która charakteryzowała się tym, że rozwijała się lokalnie, w środowiskach wiejskich lub miejskich. Ta szczególna „muzyka ludowa” - blues - szybko zdobyła popularność w ośrodkach miejskich Stanów Zjednoczonych przełomu XIX i XX wieku. W okresie rozwoju miejskiego blues cechuje się dużym tempem zmian w zakresie akompaniamentu. Początkowo muzycy bluesowi wykorzystywali akompaniament gitarowy. Popularność gitary tłumaczy się jej dostępnością oraz przystępną ceną. W późniejszym okresie dostrzegalna jest zmiana akompaniamentu gitarowego na pianino. Zmiana ta była spowodowana rozpowszechnieniem się bluesa w miastach, w klubach muzycznych, na scenach wodewilowych i kabaretowych itd. Okres ten cechuje rozwój takich gatunków bluesa jak blues miejski (ang. urban blues), rozwijający się równolegle z jazzem, który przenika bluesa w zakresie rytmu i stylu (klasycznym przykładem jest piosenka St. Louis Blues z roku 1914 autorstwa Williama Christophera Handy'ego) oraz ragtime, rozwijający się m.in. w środowisku Afroamerykanów w St. Louis i szczególnie popularny w latach 1895-1918 (charakterystyczny styl i rytmika gry na pianinie prezentuje np. Maple Leaf Rag autorstwa Scotta Joplina). Ponadto rolę nie do przecenienia w rozwoju muzyki w Stanach Zjednoczonych tamtego okresu odegrały firmy wysyłkowe, takie jak Montgomery Ward czy Sears, Roebuck and Company, które ze swoimi usługami docierały do wszystkich niemal zakątków kraju. Montgomery Ward rozpoczęła działalność w roku 1872; w roku 1883 katalog firmy Sears, Roebuck and Company liczył 240 stron i oferował ponad 10 tysięcy produktów. 
pojawienie się różnych grup etnicznych w przestrzeni kultury popularnej i wreszcie rozwój technologiczny.

Wiek XX przyniósł pogłębienie związków politycznych, ekonomicznych i kulturowych między Stanami Zjednoczonymi i Wielką Brytanią (zob. punkt 3.3.); nie bez znaczenia była tu obecność amerykańskich żołnierzy w Wielkiej Brytanii podczas II wojny światowej oraz późniejszy Plan Marshalla.

Nie sposób wymienić tu wszystkich zjawisk, które przyczyniły się do popularności rock and rolla, ale nawet tak skrótowy zarys pozwala zorientować się, z jakim skomplikowanym zjawiskiem mierzy się Stanisławek i gdzie tkwią słabości proponowanych tez.

\subsection{Wpływ na zmianę kultury II wojny światowej - kontekst an- tropologiczny}

Dlaczego cezury czasowej WRO nie przesunąć np. na rok 1939? Wybuchy II wojny światowej, który oprócz ogromu tragedii ludzkich przyniósł także nieodwracalne zmiany w strukturach społecznych w Europie. Zmiany dotyczyły nie tylko obszaru politycznego czy ekonomicznego, ale przede wszystkim kulturowego. Przykładowo w Wielkiej Brytanii impulsem inicjującym zmiany w stylu życia, obyczajów i mody było rozlokowanie dużej ilości wojsk amerykańskich. Przypomnę, że siły wojskowe Stanów Zjednoczonych w Wielkiej Brytanii liczyły ogółem ok. 433 tysięcy żołnierzy ${ }^{54}$. Rozlokowanie tak dużej liczby żołnierzy w bazach wojskowych rozproszonych na terytorium całego kraju wywarło znaczący wpływ na lokalne społeczności. Nawiązywanie bliższych relacji sprzyjało przenikaniu się kultur, przejmowaniu mód, łącznie z muzyką, stylami ubierania się, żywieniem.

Zmianie uległy także stosunki wewnątrz brytyjskich grup społecznych, np. przyśpieszył się proces emancypacji kobiet - szacuje się, że w roku 1943 w zawodach typowo męskich (inżynieria, metalurgia, przemysł chemiczny, transport) pracowało od 6 do 7 milionów kobiet ${ }^{55}$.

\footnotetext{
54 Wg danych z 30 kwietnia 1945 roku, por. https://www.abmc.gov/news-events/news/americans-great-britain-world-war-ii-online-interactive-released\#.Wgx20uFaOUk, dostęp: 15.11.2017.

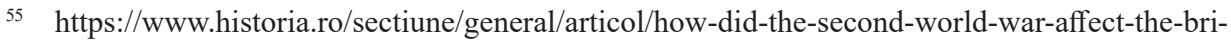


Ponadto w latach 40. XX wieku w Wielkiej Brytanii zostają implementowane zjawiska kulturowe utrwalone w Stanach Zjednoczonych, m.in. sposoby spędzania wolnego czasu (socjalizacja); rozpowszechnianie muzyki popularnej czy moda związana z muzyką (radio nadające muzykę popularną to stacja Luxemburg); konsumpcyjne (zniesienie reglamentacji mięsa w Wielkiej Brytanii 1954), migracje ludności, itd.

Powstaje nowe społeczeństwo brytyjskie - bardziej mobilne (ludzie zmieniają miejsce zamieszkania przenosząc się za pracą), z silną klasą robotniczą (ok. 690 tysięcy aktywnych zawodowo górników). Dochodzi też do kolejnych zmian w sferze obyczajowej, m.in. wzrasta liczba rozwodów (spowodowanych m.in. powrotem żołnierzy amerykańskich po zakończeniu działań wojennych do kraju - USA); wzrasta także liczba urodzin dzieci nieślubnych (także ze związków nieformalnych), itd.

Szybciej wśród społeczeństwa brytyjskiego rozpowszechniają się formy rozrywki popularnej, np. kino; w roku 1955 zostaje uruchomiona telewizja komercyjna; w roku 1956 Wielka Brytania i Stany Zjednoczone zostają połączone transatlantyckim kablem telefonicznym - TAT1.

Rozpoczyna się także pokoleniowa zmiana światopoglądowa np. w zakresie mody (Teddy Boy oraz Teddy Girl); wzrastają także silne nastroje ksenofobiczne, np. napływ innych etnicznie grup zmusił władze brytyjskie do przyjęcia prawa Race Relations Act (1965) zakazującego rasowej dyskryminacji w miejscach publicznych ${ }^{56}$.

Lata powojenne 1946-1952 przyniosły kolejne zmiany, zarówno samoistne jak i celowe. Przykładem może tu być plan Marshalla - wdrażany od kwietnia 1948 do grudnia 1951, który ewidentnie przyczynił się do przyśpieszenia procesów integracyjnych Europy w płaszczyźnie gospodarczej i kulturowej ${ }^{57}$.

tish-society, dostęp 15.11.2017. II wojna światowa kosztowała Stany Zjednoczone 300 miliardów dolarów (1945), straty w ludziach wyniosły 300 tysięcy.

56 Na podstawie podręcznika do historii brytyjskiej (Szkoła Podstawa) - How has life in Britain change since 1948? Key Stages 2 History. Lesson Support material for Primary teachers. Materiał przygotowany przez BT.

http://www.connected-earth.com/Learningresources/HowhaslifeinBritainchanged/Lessonsupportmaterial/Lessonsupportmaterial.pdf, dostęp: 15.11.2017; inne: http://www.primaryhomeworkhelp.co.uk/war/changessince.htm, dostęp: 15.11.2017.

57 European Recovery Program, ERP, dysponujący budżetem wysokości 13 miliardów dolarów; 
Zmiany, o których wspomniałem wyżej, nie zniszczyły (kulturowo) tradycyjnego społeczeństwa brytyjskiego, lecz przekształciły je w zupełnie inny byt (kulturowy) ${ }^{58}$. Powstanie nowych jakości w kulturze brytyjskiej było samoistne (przypadkowe) w zakresie relacji społecznych oraz niesamoistne (celowe) w zakresie gospodarczego planowania strategicznego, np. centralnego kierowania produkcją rolną.

W powyższym kontekście należy podkreślić, iż teza, pojawienie się rock and rolla zapoczątkowało WRO, jest uproszczeniem, gdyż pomija złożone procesy kulturotwórcze wywołane wybuchem II wojny światowej.

\subsection{Moda - bikini}

W „WRO” został pominięty kontekst historyczny, który naświetla okoliczności wynalezienia bikini i wyjaśnia dlaczego bikini jest najmniejszym strojem kąpielowym. W roku 1946 ogłoszono konkurs: Most Beautiful Swimmer (1946), którego głównym wymogiem było zaprojektowanie najmniejszego stroju kąpielowego. Stój taki zaprojektowali niemal równolegle Louis Réard oraz Jacques Heim.

W powyższym kontekście Stanisławek pisze: „Na pierwszym pokazie kostium zaprezentowała tancerka kabaretowa, ponieważ żadna modelka nie chciała w nim wystąicic" 59 .

Konieczne jest w tym miejscu uzupełnienie.

Pierwszy pokaz najmniejszego stroju kąpielowego odbył się 5 czerwca 1946 w hotelu Piscine Molitor w Paryżu, gdzie Heim zaprezentował dwuczęściowy strój kąpielowy o nazwie „atom”. Nieco później, bo latem 1946 roku podczas pokazu mody w Cannes swój najmniejszy strój kąpielowy zaprezentował Réard. Réard opatentował swój projekt, co utrwaliło formalnie jego pozycję jako wynalazcy; jednakże pierwszym był Heim. Réard był także pomysłodawcą nazwy „,bikini”, która pochodzi od nazwy

Wielka Brytania otrzymała $26 \%$, Francja $18 \%$, Niemcy Zachodnie 11\%); por. G. Behrman: The Most Notable Adventure: The Marshall Plan and the Time When America Helped Save Europe. Free Press. Kindle Edition 2007.

58 Por. L. Hervieux, Forgotten: The Untold Story of D-Day's Black Heros, at Home and at War. Harper. Kindle Edition 2015.

59 J. Stanisławek, dz. cyt., s. 85. 
atolu w archipelagu Wysp Marshalla na Oceanie Spokojnym. Kabaretową tancerką była Micheline Bernardini, która była tzw. nude dancer w Casino de Paris, przy rue de Clichy 16 (w 9 dzielnicy) ${ }^{60}$; warto dodać, że Casino de Paris to jedna z najbardziej znanych scen Paryża i Europie XX wieku.

Podobnie jak w przypadku rock and rolla „WRO” pomija szerszy kontekst zmian społecznych, politycznych i ekonomicznych, których bikini jest wytworem. Przypomnę, że 1 czerwca 1946 roku jest symboliczną datą rozpoczęcia wyścigu zbrojeń. O 9 rano tamtego dnia zostaje przeprowadzony przez Stany Zjednoczone próbny wybuch bomby atomowej (23 000 ton) na Pacyfiku, na atolu Bikini. Przygotowania do tej próby (m.in. wysiedlenie mieszkańców) oraz jej przebieg były szeroko komentowane w prasie tamtego okresu. Próba miała na celu ulepszenie techniki wojskowej, ale także miała wymiar propagandowy: zawierała jasny przekaz dla ZSRR dotyczący przewagi Stanów Zjednoczonych w obszarze technologii militarnej. W prasie zachodniej pojawiły się wtedy alarmistyczne spekulacje na temat możliwości zagłady życia na całej planecie w wyniku eksplozji nuklearnej, słowo „Bikini” zaś stało się powszechnie znane i jednoznacznie kojarzone. Inspiracją dla Réarda i Heima były właśnie te wydarzenia (przypomnę: Heim nazwał swój strój kąpielowy „Atom”).

Zwróćmy też uwagę, że dwuczęściowe stroje kąpielowe w roku 1946 nie są zjawiskiem wyjątkowym. Zainteresowanie projektantów mody dwuczęściowym kostiumem kąpielowy w tamtym czasie było z jednej strony podyktowane względami oszczędnościowymi, z drugiej zaś stanowiło kontynuację trendów przedwojennych ${ }^{61}$ oraz wpisywało się w dynamiczny rozwój branży turystycznej, do którego przyczyniło się wprowadzenie płatnych urlopów dla klasy robotniczej (np. w Wielkiej Brytanii wprowadzono płatne wakacje w roku 1938 na podstawie Holidays with Pay Act, 1938). Na koniec - mówiąc pół żartem, pół serio - dociekliwy archeolog mógłby sfalsyfikować ,rewolucyjność” kostiumu bikini, wskazując na mozaikę datowaną na III lub IV wiek naszej ery, na której

\footnotetext{
60 Por. https://www.pinterest.com/pin/53128470574745870/, dostęp: 15.11.2017.

${ }^{61}$ Przykładowo fotografia Avy Gardner z 4 lipca 1943 roku, na którym aktorka jest ubrana w dwuczęściowy strój kąpielowy.
} 
przedstawiono dwie kobiety w dwuczęściowych kostiumach, prawdopodobnie kąpielowych (zachowało się kilka podobnych mozaik) - chodzi tu o mozaikę z Villa Romana del Casale w Piazza Armerina (Sycylia), której właścicielem prawdopodobnie był cesarz rzymski Maksymian (Marcus Aurelius Valerius Maximianus) ${ }^{62}$.

\section{Zakończenie}

Czy propozycja WRO nie powinna uwzględniać faktów empirycznych? Jeżeli tego oczekujemy od propozycji deskryptywnych, to proponowany podział na $\mathrm{K}_{\mathrm{T}} \mathrm{i} \mathrm{K}_{\mathrm{W}}$ nie wytrzymuje konfrontacji z faktami, których przecież nie sposób zignorować bez narażenia się na zarzut normatywności opisu. Podjęcie krytyki WRO oraz zarysowanie tła, na którym przebiegały przywołane przez Autora wydarzenia, było konieczne z kilku powodów.

Pierwszym jest zwrócenie uwagi, że badania kulturoznawcze w Polsce dawno już wyszły poza etap wstępnych poszukiwań. Współcześnie oczekuje się, że opis aktualnych zjawisk kultury będzie udokumentowany, co wiąże się z koniecznością zgromadzenia danych, w oparciu na których sformułuje się hipotezy. W przypadku minionych zjawisk kultury obowiązuje metodologia badań historycznych, co wiąże się z poszukiwaniem źródeł nie tylko owe zjawiska opisujących, ale także wskazanie przyczyn i skutków ich korelacji. W przeciwnym wypadku oddalamy się od badania zjawisk kultury w kierunku np. normatywności. Mówiąc wprost, przechodzimy tu do idealizacji opisu zjawisk kultury, co może prowadzić np. do ich mitologizacji. Kwestią sporną pozostanie to, czy opis zjawiska kulturowego w taki sposób, jak to zostało zaproponowane w postaci tez WRO, jest logicznie i analitycznie spójny. Jeżeli tak nie jest należy WRO albo uzupełnić, albo odrzucić. Opozycja $\mathrm{K}_{\mathrm{T}} \mathrm{i} \mathrm{K}_{\mathrm{W}}$ oraz wskazane artefakty - rock and roll i bikini - które są dowodem rozpoczęcia WRO musi być potraktowana jako ciekawostka, pozwalająca na dalsze dyskusje. Na obecnym etapie z propozycji WRO wynika jednak ważny wniosek. Okazuje się, że skonstruowanie całościowej teorii WRO

62 Por. http://www.radioluce.it/2016/01/03/terminati-i-restauri-alla-villa-romana-del-casale-di-piazza-armerina-2/, dostęp: 15.11.2017. 
jest trudne ${ }^{63}$, ponieważ, przykładowo: (1) każdy opis jest zatrzymaniem w czasie, jest statycznym obrazem dynamicznych procesów; (2) nie jest możliwe wskazuje momentu początkowego zjawisk; (3) ilość oddziałujących na siebie i wchodzących w interakcje przyczynowe i skutkowe zjawisk jest ogromna (np. 1024), co utrudnia (lub uniemożliwia) ich poznanie; itd. Zauważmy, że impulsem do rewolucji obyczajowych są, z jednej strony, innowacyjne ,pomysły” ludzi wybitnych (lub szaleńców), którzy mają możliwość (lub zdolność) przekonania szerokich warstw społecznych do atrakcyjności owego „pomysłu”; z drugiej zaś procesy społeczne zachodzące spontanicznie, bez autorskiego wpływu konkretnych jednostek. Jednostka wchodząc w kontinuum kultury wkracza w przestrzeń różnorodnych, jednoczesnych i niezrozumiałych dla siebie zjawisk, które stara się zrozumieć, lecz nie zawsze robi to w sposób właściwy. Ów poznawczy irracjonalizm towarzyszy człowiekowi od zawsze. I tu należy zgodzić się z tezami WRO, że postęp technologiczny jest dla nas wyzwaniem. Zwłaszcza wpływ technologii cyfrowej na życie i sposoby myślenia człowieka o świecie. Dla człowieka, który tkwi w wieku analogowym przejście do świata cyfrowego może być bolesnym i trudnym do przebycia etapem. Inaczej rzecz przedstawia się w przypadku człowieka, którego doświadczenia dotyczą tylko świata cyfrowego. Spór ontologiczno-epistemologiczny o istnienie świata $\mathrm{w}$ rozumieniu człowieka analogowego i człowieka cyfrowego jest aktualnym problemem i dotyczy, mówiąc najprościej, całych społeczeństw. Pokazuje to, że przed „humanistyką wieku cyfrowego", a przede wszystkim filozofią kultury, stoją bardzo poważne wyzwania.

\section{Summary}

The article is critical of the theses presented in J. Stanisławek's article Wspólczesna rewolucja obyczajowa [The contemporary revolution of manners] (hereafter WRO), which introduces the categories of (1) 'traditional culture' and (2) 'contemporary culture', to which attributes are assigned: to the former, elitism, idealism, and asceticism; to the latter, ega-

63 W moim przekonaniu nie jest to możliwe. 
litarianism, utilitarianism, and hedonism. It also characterises traditional culture as being oriented towards the realisation of ideals, contemporary culture towards pleasure. The beginning of the collapse of the values of traditional culture is supposed to have been determined by the appearance in Western Europe of rock and roll and the bikini. The main objections to WRO concern: (1) omission of a historical-cultural context; (2) failure to base the analysis on factual data; (3) dichotomous division of categories; (4) ethnocentric evaluation of categories. Stanisławek's article is part and parcel of the war of cultures, i.e. the conflict between conservative and liberal visions of the world (social relations).

Key words: theory of culture, war of cultures, anthropological aggression, ethnocentrism. 